\title{
С.Н. Касаткин
}

\section{ПРОБЛЕМЫ СПЕЦИФИКАЦИИ ЮРИДИЧЕСКОГО ЯЗЫКА В УЧЕНИИ ГЕРБЕРТА ХАРТА 1949 ГОДА*}

\begin{abstract}
Исследуется концепция юридического дискурса британского философа Г.Л.А. Харта, предложенная в очерке 1949 года и составившая основу авторского проекта аналитической юриспруденции. На базе текстов и методологии Харта обсуждаются особенности юридического дискурса и сложности в его спецификации, вытекающие из дуализма авторской идеи аскриптивности, а также из характера и целей концепции автора (направленной на критику логико-дескриптивной философии и прояснение обыденного языка через язык юридический).

Ключевые слова: Г.Л.А. Харт, юридический язык, правовые понятия, аскриптивность.
\end{abstract}

Объяснение специфики юридического языка- одна из важных тем в творчестве британского философа-аналитика и правоведа Герберта Харта. Однако в его работах не содержится четкого определения юридического дискурса и его границ, что создает сложности в понимании и использовании его концепции, порождая различные ее трактовки в зарубежной и отечественной литературе. В свете сказанного мы обратимся к раннему очерку Харта 1949 г. [1], где им впервые выдвигается тезис об особенностях юридического языка, который переходит в измененном виде в работы 1950-х гг. как один из центральных для методологии аналитической юриспруденции. От изложения ключевых позиций очерка мы перейдем к обсуждению выделяемых автором свойств юридического дискурса (прежде всего аскриптивности) и связанных с этим проблем в его спецификации.

1. Концепция аскриптивизма и отменяемости понятий 1949 года. Очерк Харта «Приписывание ответственности и прав» ориентирован на постановку именно философских (а не юридических) проблем и их решение в свете идей аналитической лингвистической философии, прежде всего взглядов Дж.Л. Остина. Главными мишенями авторской критики выступают доктрины дескриптивизма (истолкования языка как системы описаний) и логищизма (претензии на первенство и универсализм логической трактовки языка). В противовес последним Харт заявляет свой базовый тезис о неописательности и аскриптивности предложений/высказываний типа «Он сделал это» и соответствующем неописательном, аскриптивном характере понятия действия: «Моя основная цель в данной статье - выдвинуть предположение о том, что философский анализ понятия человеческого действия был... неадекватным и сбивающим с толку, поскольку предложения формы “Он сделал это” традиционно рассматривались в первую очередь как описательные, тогда как их основная функция - та, которую я осмеливаюсь

\footnotetext{
* Публикация подготовлена в рамках поддержанного РГНФ научного проекта № 16-03-00804.
} 
называть аскриптивной, - вполне буквально состоит в том, чтобы приписывать ответственность за действия, во многом так же, как основная функция предложений формы “Это - его” заключается в том, чтобы приписывать права собственности» [1. С. 343]. И далее: «...Я хотел бы обосновать... тезис о том, что понятие человеческого действия есть аскриптивное [понятие]... Предложения “Я сделал это”, “Вы сделали это”, “Он сделал это” представляют собой первичные высказывания, посредством которых мы признаем или допускаем обязанность, выдвигаем обвинения либо приписываем ответственность» [1. С. 360]. Иными словами, по Харту, говоря «Он сделал это», мы не (просто) описываем некий материальный факт («действие»), но вменяем лицу за него ответственность. Мы совершаем определенный речевой акт (в духе «перформатива» Остина), который базируется на отличных от дескрипции основаниях и не может объясняться с помощью привычной «теоретической модели описательных утверждений».

Для обоснования подобных тезисов Харт и обращается к юридическому словоупотреблению: «[Приведенные обыденные] аскриптивные предложения... в некоторых важных аспектах напоминают официальные исковые заявления, обвинения, признания, судебные решения и вердикты, образующие столь обширную и столь значимую часть языка юристов. И понять логические особенности, отличающие эти виды предложений от предложений описательных... можно лучше всего через рассмотрение некоторых характеристик правовых понятий, поскольку таковые представлены в юридической практике и судопроизводстве, нежели в теоретических спорах о правовых понятиях, которые ведутся правоведами, подверженными влиянию философских теорий» [1. С. 343-344].

В числе таких «логических» характеристик правовых понятий в очерке 1949 года называются их неопределенность и отменяемость, которые, согласно Харту, делают бессмысленным применение к ним закрытых логических дефиниций («языка необходимых и достаточных условий»). С одной стороны, по мнению автора, классическая дефиниция игнорирует открытость терминологии (прецедентной) правовой системы, отсутствие здесь строгих всеохватывающих определений и широкое судейское усмотрение, что не позволяет составить четкий закрытый перечень оснований использования юридического термина. Отсюда установление значения понятий возможно лишь через апелляцию к прошлым прецедентам (образцовым случаям применения понятий) в сочетании с выражением «и так далее», т.е. в единстве с констатацией открытости и возможной новизны будущих употреблений [1. С. 345]. С другой стороны, классическая дефиниция не учитывает презюмируемую применимость юридических понятий. По наблюдениям Харта, оспаривание юридических заявлений возможно как через отрицание фактов, лежащих в основе таких заявлений, так и через обращение к иным, прямо не связанным с данными фактами обстоятельствам («исключениям»), способным полностью отменить первоначальное заявление или «ослабить» его. Отсюда, согласно автору, определение, например, такого понятия, как договор, через положительные условия, требуемые правом для его действительности (наличие двух сторон, предложения, его принятия и др.), будет неполным, поскольку «указанные условия, хотя и являются необходимыми, не всегда дос- 
таточны... [Нам] все еще придется узнать то, что может отменить заявление о наличии действительного договора [обман, ошибка, принуждение, недееспособность и пр.], даже если все эти условия удовлетворены» [1. С. 346]. Договор, таким образом, является «отменяемым понятием», которое «подвержено аннулированию или отмене по ряду различных условленных обстоятельств, но продолжает... [применяться], если такие обстоятельства не наступили» [1. С. 347]. При этом, по мысли Харта, положительные и отрицательные условия применения правовых понятий асимметричны и несводимы друг к другу, различаясь по своим речевым, «логико-процессуальным» характеристикам, а равно отношению к фактам, значимым для речевой квалификации (среди прочего исключения численно неограниченны и носят открытый характер, что затрудняет их предварительную исчерпывающую формализацию). Отсюда значение подобных понятий должно определяться «через исключения», посредством фиксации положительных условий в сочетании с выражением «если не», т.е. с их дополнением условиями отрицательными [1. § I].

Фиксируя «открытость» и сложность оснований словоупотребления (прежде всего через доктрину отменяемости), Харт тем самым подчеркивает несводимость юридических понятий и утверждений к констатации материальных фактов, иначе говоря, их аскриптивность. По мысли философа, устанавливая, существует ли действительный договор между А и В, судья не просто отвечает «Да» или «Нет» на вопрос «Подпадают ли факты под формулу, определяющую необходимые и достаточные условия применения понятия “договор”?»: заключение судьи - это решение, подкрепленное фактами и уместное в отсутствие иных заявлений или обстоятельств. Судебные решения (а также иски, обвинения и пр.) всегда суть «смеси» факта и нормы, которые могут быть правильными или неправильными, хорошими или плохими, но не могут называться истинными или ложными, логически необходимыми или бессмысленными [1. С. 355].

Исходя из этого, Харт показывает представленность названных черт юридического языка, прежде всего неописательности/аскриптивности употребления, в повседневной речи: в случаях использования специальной терминологии права («Это - мой договор со Смитом», «Вчера мой отец составлял завещание» и др.) и применения близких ей обыденных выражений [1. $\S$ II]. Автор пишет: «[Присмотритесь]... к предложениям, где используемые слова выводят свое значение из правовых или социальных институтов (например, института собственности), будучи при этом обычными неспециальными словами... “Это - мое”, “Это - ваше”, “Это - его” являются в первую очередь предложениями, для которых юристы создали выражение “оперативные слова”, а г-н Дж.Л. Остин - термин “перформаторный”... [Произнося таковые]... особенно в настоящем времени, мы часто не описываем, но, по сути... совершаем действие... заявляем права на собственность, даруем или передаем заявленные права, признаем или приписываем такие права... [И] когда эти слова употребляются подобным образом, они связаны с подкрепляющими их фактами во многом так же, как и судейское решение. Но помимо этого, данным предложениям, особенно в прошлом и будущем времени, 
присуще разнообразие иных форм использования, трудно отделимых от того, что я назвал их первичным употреблением...» [1. С. 357-358].

Аналогия юридического и обыденного дискурсов распространяется Хартом далее - на обоснование итогового тезиса об аскриптивности понятия действия (несводимого к описанию психически обусловленных движений тела) и первичного употребления предложений «Я сделал это», «Вы сделали это», «Он сделал это» (как речевых актов признания обязанности, выдвижения обвинения или приписывания ответственности): «..Смысл, в котором наши действия являются нашими, во многом схож со смыслом, в котором нашей является собственность... Сравните с традиционным вопросом о действии [«Что отличает движение человеческого тела от человеческого действия?»] вопрос “В чем разница между частью земли и частью собственности?”. Собственность не является описательным понятием, и различие между предложениями “Это - часть земли” или “Смит удерживает часть земли”... и предложениями “Это - чья-то собственность” и “Смит владеет частью собственности”... нельзя объяснить без обращения к неописательным высказываниям, посредством которых провозглашаются правовые нормы и выносятся решения или... признаются права.... Также и разницу между предложениями "Его тело двинулось в насильственное соприкосновение с телом другого" и “Он сделал это” (...“Он ударил ее”) нельзя объяснить без обращения к неописательному употреблению предложений, посредством которых приписываются обязанности или ответственность. Что в корне неправильно... [в традиционном анализе действия] так это ошибочное отождествление... значения неописательного высказывания, приписывающего ответственность... с фактическими обстоятельствами, которые подкрепляют такое приписывание или являются для него надлежащими основаниями... Наше понятие действия, как и наше понятие собственности, есть понятие социальное и логически зависимое от принятых правил поведения. Оно по своей сути не является описательным понятием, но по природе аскриптивно. И оно является отменяемым понятием, подлежащим определению посредством исключений, а не через совокупность необходимых и достаточных условий, физических или психологических» [1. С. 360-362].

Таким образом, в очерке 1949 года Харт придерживается следующей линии обоснования. Аргументируя свой базовый тезис о неописательности и аскриптивности понятия действия, автор формулирует общие тезисы отменяемости и аскриптивности словоупотребления, выявляя специфику интересующих его форм обыденного языка через анализ юридического дискурса. Именно в рамках данной логики он раскрывает особенности правовых понятий и их применения.

2. Доктрина 1949 года и особенности юридического языка. Как в подобном контексте характеризуется юридический язык? Как отмечалось, ни в очерке 1949 года, ни впоследствии Харт не дает его четкой спецификации и, судя по всему, не ставит для себя такой цели. Вместе с тем в работах автора присутствуют характеристики юридического дискурса, значимые при обсуждении его специфики, «аномалии».

Во-первых, можно говорить о ряде общих параметров юридического дискурса, обнаруживаемых в очерке 1949 года (и работах 1950-х гг.), которые 
сопряжены с разделяемой Хартом методологией философсколингвистического анализа. Подобно иным языкам, юридический дискурс мыслится автором как речевая практика, противопоставленная оторванным от непосредственного словоупотребления теоретическим моделям (по Остину, «кабинетной философии») и имеющая приоритет в качестве основы исследования [1. С. 343; 2. § I]. В этом контексте юридический дискурс выступает особой и обособленной формой словоупотребления, несводимой ни к более свободному, четко неопределенному и нерефлексивному обыденному языку (в духе моделей Остина и Витгенштейна), ни к более строгому, предельно абстрактному и универсализированному аппарату эмпирической науки или логики $[1,2]$.

Во-вторых, по заявлениям Харта, «типологически» юридический языкэто прежде всего язык нормативный, институцииональный, «особый сегмент человеческой речи», связанный «с провозглашением и применением правил» [2. С. 376] (в связи с чем в интерпретации автора юридические заключения представляют собой «смеси факта и права», а юридические нормы суть «не логические или лингвистические правила, но в огромной степени правила для принятия решений» [1. С. 344, 356]). Значение и употребление ключевых юридических выражений, по Харту, задано правом как социальным институтом [13. С. 357; 2. С. 399], его нормами, конвенциями, процедурами, соответствующим опытом и речевыми навыками членов сообщества, их «внутренней точкой зрения» (принятием и использованием данных норм как стандартов поведения и оценки) [3]. При этом в работах 1949-1950-х гг. автор мыслит юридическое словоупотребление именно в связи с действующим в обществе правом (т.е. как дискурс судопроизводства или практики совершения юридических актов $[1,2,3])$, не вдаваясь в споры о правопонимании и «правовых» критериях спецификации языка.

В-третьих, отличие юридического дискурса может усматриваться в его аскриптивности, центрируемой Хартом в очерке 1949 года (позиция, представленная в отечественной литературе [4, 5, 6; 7]). Однако непроясненность используемого философом «аппарата» аскриптивности - равно как отменяемости и неопределенности - не позволяет четко специфицировать юридический язык. Среди прочего Харт не различает два смысла (источника) неописательности как отсутствия эмпирических референтов и как неконстативности, смешивая семантические и прагматические аспекты аскриптивности - приписывание соционормативного значения и производство речевого действия [8. Гл. 2. § 1, 5]. Отсюда из текста 1949 года (да и работ 1950-х гг.) остается неясным, связаны ли особенности юридического языка со специильной лексикой («социальными» / нефактуальными и отменяемыми понятиями, их «логическими» свойствами) или с особой речевой функцией (нормативным типом рассуждения и действия) либо, возможно, с их соединением? Можно ли, например, обоснованно говорить о юридическом языке при описательном употреблении юридических терминов либо при официальном использовании обычных выражений?

Как представляется, учению Харта лучше всего подходит тезис, согласно которому любой термин или понятие может считаться (в широком смысле) правовым, если используется в рамках конкретной юридической практики / 
правовой системы и приобретает тем самым особое юридическое значение, способ и основания употребления. Подобный взгляд можно усмотреть, например, в дифференциации философом обыденной и юридической причинности [9] или в обсуждении языка корпораций, когда он пишет об «особом способе употребления» в праве обычных слов, об их «соответствующем приспособлении», о «сдвиге» или «расширении [их] значения» [2. С. 388-389, 399] («...Любые слова или фразы, соединяясь с названиями корпораций, приобретают особое юридическое употребление, ибо в подобных случаях эти слова соотносятся с фактами не только посредством правил обыденного английского языка, но и посредством норм английского права, во многом так же, как в ситуации, когда мы расширяем значение слов... “брать” (take) или “терять” (lose), используя их применительно к взяткам в игре в карты, они соотносятся с фактами уже посредством правил игры» [2. С. 399]). Это, в свою очередь, означает подвижность состава юридического языка и его границ с обыденным дискурсом. Кроме того, при данной трактовке сохраняется защищаемая Хартом «первичность», базовость для юридической речи нормативного типа изъяснения (т.е. аскриптивности как конституирующей нормативности). Таковой, с одной стороны, определяет применение в праве «обычных» (и любых других) слов, их связь с фактуальными референтами, с другой - учреждает специальную понятийно-лексическую систему, существующую лишь благодаря институту права (с ее возможным и производным распространением на иные сферы дискурса) [8. Гл. 2. § 1].

В связи с этим обратим внимание на трактовку концепции Харта Т. Коулом [10] (схожий взгляд также воспроизводится у В.В. Оглезнева с акцентом на связь правовых понятий с их реализацией в рамках формальных процедур [5. С. 119 и др.]). Поскольку, замечает Коул, по Харту, правовые понятия неопределенны, слабо регулируются прецедентами и зависят от широкого усмотрения должностных лиц, их нельзя определить через правила словесного перевода в иные термины или строгую логическую формулу: юридическое выражение нельзя четко соотнести с выражением в обыденном языке. Отсюда употребление официальных оборотов обычными гражданами не означает использование юридического языка, ибо обыватели не обладают необходимой квалификацией для надлежащего толкования и применения правовых норм и, как следствие, для определения и разъяснения правовых понятий. Таким образом, заключает Коул, юридический язык у Харта - это особый профессиональный язык, тесно связанный с социальными правилами о надлежащем исполнении своей роли юристами и судьями [10. Р. 45-48].

Приведенная трактовка - заслуживающая отдельного рассмотрения - coдержит важную проблематизацию существа и границ юридического языка. Однако, как полагаем, даже будучи выводимой из текста 1949 года, она имеет с доктриной Харта значимые расхождения. Начнем с том, что Харт, судя по всему, не выступает со столь радикальным тезисом неопределенности ни в 1949 году, ни впоследствии. Конечно, правовые понятия обладают некоторой степенью неопределенности, препятствующей их логической дефиниции. Однако, согласно автору, такие понятия и основанные на них правила обладают минимумом определенности («ядром значения»), необходимым для обеспечения руководства и коммуникации [3. Ch. 7 § I]. Данный тезис проис- 
текает из базовой для философа лингво-аналитической доктрины значения и проявляется затем в отрицании им нормативного скептицизма [3. Ch. 7 II]. Далее, хотя позиция юристов, точнее должностных лиц, играет здесь важную, и даже ключевую, роль (в том числе в связи с фиксацией содержания правила признания), юридический язык не мыслится Хартом как доступный лишь юристам, а юридические правила видятся как нормы, пригодные для правовой системы в целом, даже в «пограничных» правопорядках [3. Р. 112-113]. Последнее, например, выражается в несводимости права к системе итоговых решений инстанций в силу связанности последних принятыми в обществе правовыми стандартами [3. Ch. 7 § III]. Наконец, подчеркнем, что выводы Коула не просто отсутствуют у Харта, но вообще не охватываются его рассуждениями. Философ не нацелен на спецификацию юридического языка или дифференциацию его действия для юристов и обычных граждан. Главное для него - вскрытие неописательного/аскриптивного характера ряда выражений, что наиболее очевидно на примере официальной речевой практики.

В-четвертых, при оценке заявлений Харта об особенностях юридического языка - включая тезис об аскриптивности - следует учитывать непроясненность степени универсальности авторских утверждений, его молчание по вопросу о том, насколько та или иная отличительная черта уникальна или привычна для иных типов словоупотребления. Так, в очерке 1949 года Харт отстаивает неописательность и отменяемость понятий юридического языка (договор, преступление и др.), которые, по его мнению, присущи и ряду образований повседневного дискурса (понятиям собственности и действия). При этом аргументация философа, судя по всему, дает основания для более сильных утверждений: с одной стороны, для распространения данных черт на более широкий перечень «языковых игр», с другой - для признания нормативности и отменяемости любых речевых действий, включая производство дескрипций (что, например, очевидно из работ Дж.Л. Остина 1950-х гг. [11. Лекц. XI-XII; 12. § X] и последующего развития теории речевыХ актов). Распространенность еще одной заявленной особенности правовых понятий - их открытости/неопределенности - оставляется вообще без внимания. Позднее, в «Понятии права» (1961) Харт также провозглашает открытость юридических терминов и правил (их «структуры»/«текстуры»), однако, толкуя ее иначе: как неопределенность в пограничных случаях и как общую черту человеческого языка [3. Ch. 7§ 1].

В 1953 году Харт уже подчеркивает иные «аномалии» юридического дискурса (его базовой терминологии): разнородность в употреблении ключевых правовых терминов, отсутствие их прямой связи с фактуальными референтами, юридический вывод как функцию юридических утверждений и пр. [2] При этом здесь также не фиксируется сфера их действия. Автор сравнивает юридическое и повседневное словоупотребление, демонстрируя их аналогии (как в утверждениях «У Х есть право...» и «Он вне игры») и оппозиции (как между терминами «субъективное право» и «стул» или «кот») [2. § II-III]. Однако, как и ранее, Харт не разъясняет общей применимости данных характеристик к иным конструкциям как обыденного, так и юридического языка, а равно их соотношения с (близкими) чертами, заявленными в очерке 1949 года. Он, по сути, обсуждает лишь параметры, значимые для целей сво- 
его исследования, следуя в этом плане принятой в его кругу традиции фокусироваться на предельно конкретном, но значимом предмете анализа (разобраться с малым, создав более прочную основу для дальнейших интеллектуальных конструкций). В этом контексте тезисы Харта об особенностях юридического языка следует толковать ограничительно: их «аномальность» прописывается на фоне и в противовес господствующей и критикуемой автором философской модели языка как системы эмпирически заданных и логически упорядоченных дескрипций $[8,13]$.

В этом плане притягательной, но не вполне оправданной видится оценка очерка 1949 г. (и очерка 1953 г.), даваемая Г. Бейкером. По его мнению, Харт здесь стремится предложить «подлинное объяснение юридических понятий и утверждений», которое бы учитывало их особую природу sui generis («невозможность показать их логическую эквивалентность неправовым понятиям и утверждениям») и не сводилось бы к традиционным полюсам правовых теорий реализма и редукционизма [14. Р. 26-28]. Вопреки Бейкеру, рассуждения Харта вряд ли направлены на обоснование юридического языка как языка sui generis. Аномалии юридического словоупотребления для Харта - это частный случай более общего типа дискурса, который связан с провозглашением и применением правил и противоположен языкам эмпирического типа, а также абсолютизирующей их логико-описательной философской модели [2. § III; 13]. Предлагаемая же Бейкером проблематизация и альтернативная семантика правовых понятий (в духе Витгенштейна), как кажется, во многом близка рассуждениям самого Харта.

Схожие комментарии вызывает и позиция В.В. Оглезнева, который рассматривает черты юридического языка, прямо или имплицитно представленные в текстах Харта, как его исключительные свойства, обеспечивающие к тому же четкую дифференциацию правовых и неправовых понятий, включая противопоставление юридического языка как аскриптивного и обыденного языка как описательного [5. С. 119 и др.]. Как полагаем, в очерке 1949 г. скорее противопоставляются понятия природные (фактуально-эмпирические) и социальные (нормативно и институционально обусловленные, аскриптивные), а исследование Хартом юридических выражений используется для прояснения свойств ряда повседневных понятий, прежде всего понятия действия, что возможно именно в силу общности их характеристик. И хотя в обыденном языке имеются конструкты природно-описательного типа (такие, как «стул» или «кот»), а в очерке 1953 года упоминается о наличии прямых фактуальных референтов у большинства обычных слов [2. С. 2, 3, 12], у Харта не обнаруживается заявлений о тотальной дескриптивности повседневного дискурса. С этой точки зрения спецификация юридического языка через аскриптивность представляется скорее вариантом развития философскоаналитического проекта Харта, чем его собственной позицией. То же касается и оценки иных свойств юридического дискурса, формулируемых В.В. Оглезневым на базе текстов британского мыслителя. Так, контекстуальность и конвенциональность, на наш взгляд, выступают скорее общими свойствами словоупотребления, что следует из разделяемой Хартом лингвоаналитической методологии и суждений самого исследователя (например, из параметров обсуждаемого Хартом вымышленного дискурса сказки [5. С. 108 
и др.]). То же в пределе верно и в отношении неопределенности и отменяемости языка, рассмотренных в свете философских истоков учения Харта и его последующей доктрины об «открытой текстуре» дискурса. В 1949 году Харт обращается к этим чертам именно для демонстрации изъянов логицизма и дескриптивизма, а не для отграничения юридического языка от обыденного. И если неопределенность заявляется здесь в связи с английской прецедентной системой, то отменяемость с очевидностью полагается свойством и юридических, и обыденных понятий [1].

Таким образом, на наш взгляд и вопреки ряду позиций в зарубежной и отечественной литературе, в очерке 1949 г. (как и в работах 1950-х гг.) Г. Харт не предлагает и не стремится предложить четких критериев спецификации юридического дискурса. Вместо этого он нацелен на выявление и обоснование таких черт юридического словоупотребления, которые, по его мнению, не осознаются в современной ему мысли в силу приверженности традиционным доктринам дескриптивизма и логицизма. Иначе говоря, концепция юридического дискурса Харта - это элемент общефилософской критики и переосмысления методов анализа языка на примере частной речевой практики (а в работах 1950-х гг. - еще и реформа правоведческой методологии на базе обновленной философии языка) [8, 13]. Сказанное верно и в отношении авторской идеи аскриптивности. Таковая фиксирует черту юридического словоупотребления, упускаемую логико-философским анализом и одновременно важную для адекватного объяснения «социальных» понятий и утверждений, нормативного дискурса в целом. При этом, с одной стороны, аскриптивность у Харта не дает четкой спецификации юридического языка в силу ее двойственного истолкования (как нефактуальности понятий и как особой речевой функции утверждений), с другой - она не является и не призвана выступать в качестве универсального критерия такой спецификации. По Харту, она присуща не только юридическому языку, но и иным видам дискурса, включающим социальные или институциональные понятия и нормативный тип рассуждения/ изъяснения: совершение речевых действий с помощью правил.

\section{Литература}

1. Харт Г.Л.А. Приписывание ответственности и прав [1949] // Как определять социальные понятия? Концепция аскриптивизма и отменяемости юридического языка Герберта Харта / С.Н. Касаткин. Самара, 2014. С. 343-367.

2. Харт Г.Л.А. Определение и теория в юриспруденции [1953] // Как определять социальные понятия? Концепция аскриптивизма и отменяемости юридического языка Герберта Харта / С.Н. Касаткин. Самара, 2014. С. 369-402.

3. Hart H.L.A. The Concept of Law. $2^{\text {nd }}$ ed. Oxford, [1961] 1994.

4. Дидикин А.Б. Формирование аналитической традиции в современной философии права // $\Sigma$ ХO $\Lambda$ H. Vol. 4. № 1 (2010). C. 149-165.

5. Оллезнев В.В. Г.Л.А. Харт и формирование аналитической философии права. Томск: Изд-во Том. ун-та, 2012.

6. Оглезнев В.В., Суровиев В.A. Аналитическая философия, юридический язык и философия права. Томск: Изд-во Том. ун-та, 2016.

7. Юрьев Р.А. Понятие «действия» в аналитической философии права Г.Л.А. Харта: генезис и значение // Вестник Томского государственного университета. Философия, социология, политология. 2013. № 4 (24). 175-182. 
8. Касаткин С.Н. Как определять социальные понятия? Концепция аскриптивизма и отменяемости юридического языка Герберта Харта. Самара, 2014.

9. Hart H.L.A., Honoré T. Causation in the Law. Oxford, 1959 [1985].

10. Cole T. Doing Jurisprudence Historically: Interpreting Hart Through J.L. Austin. Warwick School of Law, Research Paper. 2010/28 (http://papers.ssrn.com/sol3/papers. cfm?abstract_id=1715178).

11. Остин Дж. Как совершать действия при помощи слов // Дж. Остин. Избранное. М., 1999. С. $13-135$.

12. Остин Джс. Смысл и сенсибилии // Дж. Остин. Избранное. М., 1999. С. 141-244.

13. Касаткин С.Н. Концепция юридического языка Герберта Харта: опыт реконструкции // Философия права. 2016. № 5.

14. Baker G.P. Defeasibility and Meaning // Law, Morality and Society. Essays in Honour of H.L.A. Hart. Oxford, 1977. P. 26-57.

Kasatkin Sergei N. Samara Law Institute of FPS of Russia (Samara, Russian Federation).

E-mail: kasatka_s@bk.ru.

DOI: $10.17223 / 1998863 X / 37 / 5$

1949 DOCTRINE

Key words: H.L.A. Hart, legal language, legal concepts, ascriptivity

The article explores a conception of legal discourse proposed by a British philosopher Herbert Hart in his essay The Ascription of Responsibilities and Rights (1949) and later formed a basis of his project of analytical jurisprudence. Features of legal discourse and complexities of its specification are discussed resting on the philosopher's texts and methodology. A view is warranted according to which in his 1949 essay (as in his 1950s works) Hart doesn't offer and doesn't seek to offer clear criteria for specification of legal discourse. Instead he fixes its certain features that do not fit into a traditional, logical and descriptive, model of language. Hence Hart's conception of legal discourse is primarily a general philosophical criticism and reinterpretation of methods of language analysis through an example of a particular speech practice. In this light the author's idea of ascriptivity is not, and isn't intended to be, a universal criterion for a specification of legal discourse. On one hand, this idea is somewhat obscure, given its ambiguous, semantic-pragmatic, use by the philosopher both as a nonfactuality of concepts and as a special speech function of statements. On the other hand, according to Hart, it belongs to different types of discourse which involve "social" or institutional concepts and a normative type of reasoning / speaking (a producing speech acts with a help of rules).

\section{References}

1. Hart, H.L.A. (2014a) Pripisyvanie otvetstvennosti i prav [1949] [Assignment of responsibility and rights [1949]]. In: Kasatkin, S.N. Kak opredelyat' sotsial'nye ponyatiya? Kontseptsiya askriptivizma i otmenyaemosti yuridicheskogo yazyka Gerberta Kharta [How to define social concepts? The concept of asceticism and the cancellation of the legal language of Herbert Hart]. Samara: Samara Academy for the Humanities. pp. 343-367.

2. Hart, H.L.A. (2014b) Opredelenie i teoriya v yurisprudentsii [1953] [Definition and theory in jurisprudence [1953]]. In: Kasatkin, S.N. Kak opredelyat' sotsial'nye ponyatiya? Kontseptsiya askriptivizma i otmenyaemosti yuridicheskogo yazyka Gerberta Kharta [How to define social concepts? The concept of asceticism and the cancellation of the legal language of Herbert Hart]. Samara: Samara Academy for the Humanities. pp. 369-402.

3. Hart, H.L.A. (1994) The Concept of Law. 2nd ed. Oxford University Press.

4. Didikin, A.B. (2010) Formirovanie analiticheskoy traditsii v sovremennoy filosofii prava [Formation of analytical tradition in the modern philosophy of law]. $\Sigma X O \Lambda H .4(1)$. pp. 149-165.

5. Ogleznev, V.V. (2012) G.L.A. Khart i formirovanie analiticheskoy filosofii prava [H.L.A. Hart and the formation of an analytical philosophy of law]. Tomsk: Tomsk State University.

6. Ogleznev, V.V. \& Surovtsev, V.A. (2016) Analiticheskaya filosofiya, yuridicheskiy yazyk $i$ filosofiya prava [Analytical philosophy, legal language and philosophy of law]. Tomsk: Tomsk State University.

7. Yuriev, R.A. (2013) The concept of "action" in the H.L.A. Hart's analytic philosophy of law: The genesis and the meaning. Vestnik Tomskogo gosudarstvennogo universiteta. Filosofiya, sotsi- 
ologiya, politologiya - Tomsk State University Journal of Philosophy, Sociology and Political Science. 4(24). pp. 175-182. (In Russian).

8. Kasatkin, S.N. (2014) Kak opredelyat' sotsial'nye ponyatiya? Kontseptsiya askriptivizma $i$ otmenyaemosti yuridicheskogo yazyka Gerberta Kharta [How to define social concepts? The concept of asceticism and the cancellation of the legal language of Herbert Hart]. Samara: Samara Academy for the Humanities.

9. Hart, H.L.A. \& Honoré, T. (1959) Causation in the Law. Oxford University Press.

10. Cole, T. (2010) Doing Jurisprudence Historically: Interpreting Hart Through J.L. Austin. Warwick School of Law, Research Paper. [Online] Available from: http://papers.ssrn.com/sol3/papers.cfm?abstract_id=1715178.

11. Austin, J. (1999a) Izbrannoe [Selected Works]. Translated from English by L.B. Makeeva, V.P. Rudnev. Moscow: Ideya-Press. pp. 13-135.

12. Austin, J. (1999b) Izbrannoe [Selected Works]. Translated from English by L.B. Makeeva, V.P. Rudnev. Moscow: Ideya-Press. pp. 141-244.

13. Kasatkin, S.N. (2016) Concept of Herbert Hart Law language: Experience of reconstruction. Filosofiya prava - The Philosophy of Law. 5(78).

14. Baker, G.P. (1977) Defeasibility and Meaning. In: Hacker, P.M.S. \& Raz, J. (eds) Law, Morality and Society. Essays in Honour of H.L.A. Hart. Oxford: Clarendon Press. pp. 26-57. 